\title{
An investigation of the roles and functions of nurse preceptors in the clinical areas
}

\author{
SC Cele, BCur E et A, University of Zululand \\ HA Gumede, BCur E et A, University of Zululand \\ BA Kubheka, MCur, University of Zululand
}

\section{Abstract}

This article explores the confusion that exists in the clinical areas concerning proper accompaniment of student nurses. There is a feeling that professional nurses in clinical areas are not always actively involved in clinical teaching. The clinical instructors and nurse educators are unable to accompany student nurses properly because of staff shortages. Some hospitals have identified one professional nurse per unit to work as a nurse preceptor for accompaniment of student nurses. This has resulted in the need to find out if the professional nurse preceptor is solving the problem of lack of student accompaniment in clinical areas.

The aim of this study therefore is to investigate the roles and functions of nurse preceptors in improving student accompaniment as compared to other professional nurses in clinical areas namely, clinical instructors, nurse educators and professional nurses working in clinical areas as viewed by student nurses themselves.

A comparative descriptive study was done in one of the hospitals in KwaZulu-Natal (Region D) on a purposely selected sample of (80) 4 years comprehensive diploma student nurses, (16) nurse preceptors and (40) randomly-selected professional nurses. Open and closed-ended questions were used for collection of data. The study revealed that the most student nurses $87,5 \%$ (70) identified nurse preceptors as playing an important role in their accompaniment as compared to other professional nurses.

Student nurses identified the following roles and functions of nurse preceptors in student accompaniment: acting as role models, acting as resource people for them, providing clinical teaching, orientate them in clinical areas, allay fears and anxieties by providing guidance, support and encouragement, demonstrate procedures, help them in solving problems they experienced and do formative and summative evaluation of student nurses. These roles were in agreement with those identified by professional nurses and nurse preceptors themselves. It was found also that nurse preceptors were experiencing many problems which need to be solved in order for them to perform their roles and functions effectively. It is recommended that even those hospitals and educational institutions that are not utilizing nurse preceptors for student accompaniment should consider them because of the contributions they make. Nurse preceptors should be allocated specifically for student accompaniment with minimal patient care responsibilities and administration of Units. In conclusion proper utilization of nurse preceptors can solve the problem of a lack of student accompaniment in clinical areas.

\section{Introduction}

The clinical practice is the area where student nurses are supposed to gain their learning experiences. It is also where they are supposed to correlate acquired theory with practice (Mellish \& Brink, 1993:227). The outcome would then be competent, efficient, mature, independent, creative and critical thinking professional nurse who should be able to render quality patient care (Mellish \& Brink, 1993:336). It is the postulate of this article that this will materialise should student nurses be accompanied in clinical areas by professional nurses of a high calibre. Furthermore, the professional nurses should not only be highly knowledgeable but they must also be readily available to student nurses.

At present it is difficult to achieve the outcomes mentioned above because there is confusion concerning the proper accompaniment of student nurses in clinical areas. The general feeling is that not all professional nurses are actively involved in clinical teaching. To solve this problem some hospitals identified a nurse preceptor who is a professional nurse, identified from existing nursing team of each Unit to accompany student nurses. This study therefore was done to determine the exact roles and functions of nurse preceptors in improving student accompaniment. This was done by comparing nurse preceptors' contributions in student accompaniment to other professional nurses namely, clinical instructors, nurse educators and other professional nurses in the Units as perceived by student nurses. According to Quinn (1995:189) the role of nurse preceptors is to assist in socialization of student nurses by orientating and guiding them in acquisition of knowledge and skills needed for patient care. It is envisaged that the views of students as recipients of clinical teaching are important in solving the existing problem of a lack of student accompaniment. 


\section{Background to the study}

A hospital in KwaZulu-Natal (Region D) was specifically chosen for the study due to the fact that it was utilizing nurse preceptors for clinical teaching of student nurses in its clinical areas during investigation. It was found that while nurse educators were expected to accompany student nurses, a shortage of staff limits them to lectures in the classroom, resulting in minimal student accompaniment. According to Troskie, Guwa and Booyens (1998:44) a shortage of nurse tutors makes it difficult for one nurse tutor to spend enough time with each student nurse. While clinical instructors from clinical departments also accompany student nurses, they are too few in number. Sometimes clinical instructors manage to demonstrate procedures to each student once or twice a week only, instead of daily demonstrations.

In clinical areas professional nurses are supposed to teach student nurses together with nurse preceptors who are professional nurses identified to act as role models for student nurses (Quinn, 1995:189). Professional nurses working in the Units see their roles as administrative and that of patient care. They do not see themselves as nurse educators since nurse preceptors are there in the clinical areas. Troskie et al. (1998:44) state that multidimensional roles of Unit managers and especially staff shortages cause patient care to take priority, with clinical teaching of student nurses not a priority.

Nurse preceptors are also allocated to assist student nurses with clinical teaching, while at the same time are expected to do Unit administration and provision of patient care. Nurse preceptors therefore accepted their roles to be more educational than administrative and patient care tasks. Quinn (1995:188) sees the role of a preceptor as a resource person for student nurses in clinical areas.

However, the problem is that when there is no nurse preceptor available in clinical areas clinical teaching of student nurses is neglected. Student accompaniment would appear a problem in all hospitals, also those utilizing clinical instructors and not nurse preceptors. There is a need for this problem to be solved by identifying one category of professional nurses to specifically do student accompaniment. Goodchild-Brown (1986:5) regards student accompaniment as a team approach consisting of clinical educators, Unit professional nurses, nurse managers and nurse tutors as resource persons.

There is a general agreement in the nursing profession that each and every professional nurse has a teaching function of student nurses. Different authors identify different roles and functions of nurse preceptors, clinical instructors, nurse educators and professional nurses in student accompaniment in clinical areas, as set out below.

\section{Roles and functions of nurse preceptors}

Mellish and Brink (1993:227) identified the roles and functions of nurse preceptors as evaluating performance and providing feedback instruction based on objectives and needs of individual student. Ewan and White (1994:84) on the other hand, identified the roles and functions of nurse preceptors as facilitators, helpers, challengers, colleagues and researchers. Reilly and Oerman (1992:263) assert that nurse preceptors should provide student nurses with a climate conducive to learning. It can therefore be concluded that the roles and functions of nurse preceptors are regarded as being of prime importance in student accompaniment.

\section{Roles of clinical instructors in student accompaniment}

Clifford (1993) cited in Tanner (1996:52) identifies the roles and functions of clinical instructors as acting as liaison, a go-between. a bridge between nursing education and the nursing service, working to build good relationships that will facilitate student learning. On the other hand Quinn (1995:186) mentions the key roles for clinical instructors as educational support for students, tutoring students and facilitating good practice for student nurses. The above roles of clinical instructors are also important because there seem to be problems facing the nursing profession about poor relationships between nursing education and nursing services, which may hinder clinical teaching for student nurses.

\section{Roles and functions of professional nurses in clinical areas for student accompaniment}

Quinn (1998:188) states that professional nurses are responsible for teaching, supervision, guidance, counselling, assessment and evaluation of student nurses in clinical areas.

\section{Roles and functions of nurse educators in student accompaniment}

Brookes and Thomas (1997:50) regard the roles and functions of nurse educators as preparing student nurses for professional practice, teaching student nurses to view clients' / patients' situations holistically and teach them to be expert decision-makers in many settings.

Even if the viewpoints on the roles and functions of professional nurses seem to be different, they all agree that the professional nurses perform almost the same functions in clinical areas in the accompaniment of student nurses. It was therefore the premise of the study that was undertaken that with guidance and support of nurse preceptors, with their proper utilization, the problem of a lack of student accompaniment in clinical areas could be constructively addressed. 


\section{Statement of the problem}

Confusion concerning the proper accompaniment of student nurses in clinical practice areas is facing the nursing profession. There is a general feeling that professional nurses are not actively involved in clinical teaching of student nurses. The clinical instructors and nurse educators are unable to accompany student nurses properly because of staff shortages and heavy workloads.

Some hospitals have identified one professional nurse from the allocated staff members in the Unit to work as a nurse preceptor to accompany student nurses in each Unit. Even if this nurse preceptor is utilized there is still a problem with student accompaniment. This problem of a lack or poor student accompaniment in clinical areas influenced the researchers to investigate the exact roles and functions of nurse preceptors in student accompaniment as compared to Unit professional nurses, clinical instructors and nurse educators as viewed by student nurses, in order to solve the problem of a lack of student accompaniment in clinical areas.

\section{Objectives of study}

1.

To determine the exact roles and functions of nurse preceptors in accompaniment of student nurses as compared to other professional nurses.

2. To determine nurse preceptors' effectiveness in their roles as clinical instructors as compared to other professional nurses.

3. To identify the problems encountered by nurse preceptors in clinical practice areas.

4. To make recommendations conceming the future roles and functions of nurse preceptors in clinical teaching.

\section{Definition of Terms}

\section{Nurse preceptor}

A nurse preceptor is understood to be a professional nurse. She/he can in a practice situation act as a resource person to student nurses while at the same time promote and participate in the delivery of patient care. This professional nurse is part of the existing nursing care team for a specific Unit.

\section{Accompaniment}

Accompaniment in nursing education is directed assistance and support extended to a student nurse by a registered Nurse or registered midwife with the aim of developing a competent and independent practitioner (SANC, 1992:8).

\section{Student nurse}

A student nurse could be either a 'degree' or a 'diploma' student. For the purposes of this article, a student is a diploma student understood to be undergoing education for four years to fulfil the South African Nursing Council requirements to become a registered nurse (General, Psychiatry and Community) and midwife (SANC, R425:1985).

\section{Clinical areas}

Clinical areas are learning opportunities situated in the practice field / or in the health service which the student utilizes under supervision of a registered nurse and midwife, and/or other experts in the health service (SANC, 1992:7).

\section{Professional nurse}

A professional nurse is an independent practitioner of the profession of nursing registered with the South African Nursing Council. She/he would be held accountable for her/his acts and omissions and is responsible to the employers and society which she/he serves, to herself / himself as well as the nursing profession for maintenance of the highest standard of professional knowledge and competence (Mellish \& Wannenburg, 1993:4).

\section{Nurse educator}

According to Brink (1989:1) a nurse educator refers to all professional nurses who have an additional qualification as nurse tutor entered behind their names in the South African Nursing Register for tutors.

\section{Clinical instructors}

A clinical instructor is a registered nurse who should have insight into teaching and learning. This nurse should therefore be an average practitioner of nursing with a very broad theoretical knowledge. This knowledge should be constantly updated to keep pace with the latest developments in medicine and nursing (Mellish \& Wannenburg, 1993:68).

\section{Clinical teaching}

Clinical teaching is teaching in a clinical nursing laboratory by means of which the student nurse is taught and accompanied towards independent practice and use of own abilities (SANC, 1992:8)

\section{Research design}

This was a comparative descriptive study designed to investigate the roles and functions of nurse preceptors in student accompaniment in clinical areas, as compared to other professional nurses, as perceived by student nurses themselves. These methods were chosen in order to get information about student accompaniment.

\section{Area of study}

Area of study was in KwaZulu-Natal Province which is divided into 8 regions $\mathrm{A}, \mathrm{B}, \mathrm{C}, \mathrm{D}, \mathrm{E}, \mathrm{F}, \mathrm{G}$ and $\mathrm{H}$. One hospital in region $\mathrm{D}$ was conveniently selected because it was the only hospital utilizing nurse preceptors for student accompaniment in this region. The few hospitals utilizing nurse preceptors are far north of the Province like Region F and H. Most hospitals 
in Region $\mathrm{D}$ are utilizing clinical instructors for student accompaniment in clinical areas. This hospital consists of 9 departments. In this study only 4 departments were included. These were the Paediatric, Orthopaedic, Surgical and Medical departments. The criteria for selection was that all had student nurses allocated in their establishment and that each Unit in these departments had a nurse preceptor allocated to accompany student nurses. The other departments did not have nurse preceptors even if they had student nurses in their establishment. Each department selected had 4 Units making a total of 16 Units.

\section{Sample and sampling}

A purposive and systematic random sampling was used in this study to select 4-year comprehensive diploma student nurses, nurse preceptors and professional nurses.

\section{Selection of nurse preceptors}

Each of the 16 wards had a nurse preceptor allocated making a total of 16 nurse preceptors. These nurse preceptors were all purposely selected for the study because they were few in numbers.

\section{Table 1 : Age distribution of respondents}

\begin{tabular}{|l|l|l|l|}
\hline ITEM & $\begin{array}{l}\text { PRECEPTORS } \\
N=16\end{array}$ & $\begin{array}{l}\text { PROFESSIONAL } \\
\text { NURSES } \\
\mathrm{N}=40\end{array}$ & $\begin{array}{l}\text { STUDENT } \\
\text { NURSES } \\
\mathrm{N}=80\end{array}$ \\
\hline AGES & $\%$ & $\%$ & $\%$ \\
\hline $18-25$ & - & 12.5 & 3.75 \\
\hline $26-35$ & 31.25 & 12.5 & 93.75 \\
\hline $36-45$ & 56.25 & 75 & 2.5 \\
\hline $46-55$ & 12.5 & - & - \\
\hline $55+$ & - & - & - \\
\hline TOTAL & 16 & 100 & 100 \\
\hline
\end{tabular}

\section{Target population}

The three groups of people that were involved in this study were as follows:

- $\quad$ Four-year comprehensive diploma student nurses irrespective of level of education and training. They were selected because they had more experience in being accompanied, from first-year to $4^{\text {th }}$ year of study as compared to other types of student nurses like bridging students, who are accompanied for 2 years only.

- $\quad$ Nurse preceptors who were professional nurses identified in the allocated staff of the Unit to accompany student nurses; at the same time involved in administration and patient care tasks. They were selected in order that student nurses mention their contributions in their accompaniment as compared to other professional nurses

- $\quad$ Professional nurses working with nurse preceptors in clinical areas also supervising student nurses were selected. Their inclusion was done so that they have input on the contributions made by nurse preceptors in student accompaniment.

Nurse educators and clinical instructors were not interviewed because they were not always working with student nurses in clinical areas.

\section{Selection of 4-year comprehensive diploma student nurses}

Each ward had 10 student nurses allocated making a total of 160 student nurses. These students were composed of 80 students doing a bridging course and 80 doing a 4-year comprehensive diploma course. In this study only the 4-year comprehensive diploma student nurses were selected. All 80 student nurses doing the 4-year comprehensive course were purposely selected for the study in order to obtain information about their accompaniment.

\section{Selection of professional nurses}

Professional nurses were selected using a systematic random sampling. Every $3^{\text {rd }}$ professional nurse was selected from the population of 120 from the four departments, until a sample of 40 was selected. This was done in order to gather information from different categories of professional nurses about the expected roles and functions of nurse preceptors regarding the accompaniment of student nurses in clinical areas.

\section{The Research instrument}

The research instruments were self-administered to all respondents in order to clarify and explain questions that were less 
understood. The instruments used were three questionnaires with open- and closed-ended questions based on literature reviewed and objectives of the study targeting 4-year comprehensive diploma student nurses, nurse preceptors and professional nurses.

\section{Questionnaire for 4-year comprehensive diploma student nurses}

This questionnaire comprised 5 sections which covered the following: demographic data, level of training, important categories of nursing personnel that contributed most in their accompaniment, contributions that were made by nursing personnel mentioned in their accompaniment, and problems experienced by student nurses.

\section{Questionnaire for nurse preceptors}

Questionnaires for nurse preceptors were divided into the following 4 sections, namely demographic data, educational information, employment history which included their experience as preceptors, number of students supervised per day and the problems they experienced in student accompaniment.

\section{Validity and reliability of the instruments}

The three questionnaires for student nurses, nurse preceptors and professional nurses were developed after reviewing literature relating to roles and functions of nurse preceptors and other professional nurses in student accompaniment. This was done in order to ensure content validity.

The instruments were tested for face and content validity by senior professional nurses, nurse educators who were research experts to detect ambiguity, check appropriateness and adequacy to collect valid information for the study. Minor changes and adjustment were done on the questionnaires. A pilot study was conducted prior to the main study on 5 nurse preceptors who were included in the study, 10 student nurses and 10 professional nurses who were not included in this study. This was done to check the suitability of the instrument. Each interview took 30-35 minutes to complete. The questionnaires were

\section{Table 2: Educational qualifications of nurse preceptors and professional nurses}

\begin{tabular}{|l|c|c|}
\hline ITEM & $\begin{array}{c}\text { PRECEPTORS } \\
\mathbf{N = 1 6}\end{array}$ & $\begin{array}{c}\text { PROFESSIONAL } \\
\text { NURSES } \\
\mathbf{N}=\mathbf{4 0}\end{array}$ \\
\hline $\begin{array}{l}\text { EDUCATIONAL } \\
\text { QUALIFICATION }\end{array}$ & $\mathbf{\%}$ & $\mathbf{\%}$ \\
\hline General nursing & 100 & 100 \\
\hline Midwfery & 100 & 30 \\
\hline Community health & 25 & 40 \\
\hline Nursing manage ment & - & 10 \\
\hline Nursing education & 25 & 30 \\
\hline Psychiatric nursing & 75 & - \\
\hline BA cur & 25 & 00 \\
\hline
\end{tabular}

roles they played in student accompaniment, and problems they experienced in the accompaniment of student nurses.

\section{Questionnaire for professional nurses}

On the other hand questionnaire for professional nurses comprised 5 sections namely, demographic data, educational information, employment history which included experience as professional nurses, number of student nurses they supervised per day and role they played in student accompaniment, role played by nurse preceptors in student accompaniment, and found to be acceptable for the study.

\section{Ethical consideration}

- $\quad$ Permission to conduct the study in the hospital concerned was obtained from the Department of Health.

- $\quad$ Furthermore, letters requesting permission to conduct the study were written to the Chief Medical Superintendent and Deputy Director of the hospital. 
Verbal consent was also obtained from all participants before conducting the study, explaining the purpose of the study and conditions of participation.

- Confidentiality of information and anonymity was guaranteed, since the information was concerned with their education, training and work situation.

\section{Data analysis and findings}

A content analysis of data was done manually by means of descriptive statistics.

\section{Demographic data}

Ages were considered to be important because it might influ- this study are concerned nurse preceptors and professional nurses were seemingly educationally well-prepared to perform their roles and functions of accompanying student nurses in clinical areas.

\section{Level of education and training of student nurses}

Table 3 reveals that student nurses were at different levels of education and training. First-years $=33,75 \%(27)$, second-years $=25 \%(20)$. third-years $=22,50 \%(18)$ and fourth years $=18,75 \%$ (15).

From the above statistics it is clear that the sample contained diploma student nurses who were of different levels of educa-

\section{Table 3: Level of education and training of student nurses}

\begin{tabular}{|l|l|l|}
\hline $\begin{array}{l}\text { LEVEL OF EDUCATION \& } \\
\text { TRAINING OF STUDENT } \\
\text { NURSES N=80 }\end{array}$ & $\begin{array}{l}\text { FREQUENCY } \\
\mathbf{N}=\mathbf{8 0}\end{array}$ & $\begin{array}{l}\text { PERCENT } \\
\mathbf{N}=\mathbf{8 0}\end{array}$ \\
\hline First Year & 27 & 33.75 \\
\hline Second Year & 20 & 25 \\
\hline Third Year & 18 & 22.50 \\
\hline Fourth Year & 15 & 18.75 \\
\hline TOTAL & $\mathbf{8 0}$ & $\mathbf{1 0 0}$ \\
\hline
\end{tabular}

ence the experience gained in student accompaniment and the level of performance of each professional nurse.

Table 1 reveals that most of nurse preceptors were between the ages of $36-45$ years, $56,25 \%$ (9). Only $12,5 \%$ (2) were $46-55$ years. Professional nurses were also mostly between the ages of 26-45 years $75 \%$ (30) and student nurses on the other hand were mostly between $26-35$ age group $93,75 \%$ (75). Therefore it was felt that the nurse preceptors and professional nurses are professionally matured enough to help student nurses since they are older than them.

\section{Educational information}

Table 2 revealed that nurse preceptors and professional nurses all had general nursing and midwifery qualifications. Only a few had additional qualifications in nursing education, nursing management, community health nursing, psychiatric nursing and a degree in nursing. Twenty-five percent (4) nurse preceptors had nursing education and none had nursing management. With professional nurses $40 \%$ (16) had nursing management and only $10 \%$ (4) had nursing education qualifications. Twenty-five percent (4) preceptors had community health nursing science as compared to $30 \%$ (12) professional nurses. Most of nurse preceptors $75 \%$ (12) had psychiatric nurses as compared to only $30 \%$ (12) with professional nurses. Over and above $25 \%$ (4) nurse preceptors had degrees in nursing which was lacking with professional nurses. As far as researchers of tion and training, which means that they had different experiences with precentorship. These differences in experiences might contribute a lot to this study. It will enable them to make constructive comments about their accompaniment in clinical areas.

\section{Employment history Employment history of nurse preceptors}

It was found that $31,25 \%$ (5) nurse preceptors were employed at the capacity of professional nurses, $37,15 \%$ (6) were senior professional nurses and $31,25 \%$ (5) were chief professional nurses. Besides doing clinical teaching nurse preceptors were also involved in ward administration, and patient care since they were employed at senior levels and were in charge of wards. This situation might hinder their function of clinical teaching. Only $31,25 \%$ (5) were ordinary professional nurses, which would be an advantage in contributing effectively to student accompaniment.

\section{Employment history of professional nurses}

Only $12,5 \%$ (5) of the professional nurses were employed as 
senior professional nurses in charge of the Units, another $12.5 \%$ (5) were chief professional nurses also in charge and only $75 \%$ (30) were employed as ordinary professional nurses. From these findings it could be said that most of professional nurses could contribute significantly to student accompaniment since they were not in senior positions as compared to only $31,25 \%$ (5) nurse preceptors who were also not in senior positions. The rest of nurse preceptors in senior positions $68,75 \%$ (11) could be prevented from doing proper student accompaniment because of multidimensional roles they perform. Proper student accompaniment can be done by a professional nurse who is not in charge of a Unit because she has more time to do so. If the professional nurse is in charge and at the same time is expected to act as a nurse preceptor, teaching student nurses, she will fail to perform all these duties properly because of a heavy workload. However Booyens (1993:272) argues that the workload of nurse preceptors should be reasonable in order to allow them sufficient time to perform their roles and functions.

\section{Experience of nurse preceptors and professional nurses}

\section{Experience of nurse preceptors in years}

According to figure $1,62,25 \%$ (10) nurse preceptors had 1 year experience as nurse preceptors, $31,25 \%$ (5) had between 2-3 years and only $6,25 \%$ (1) had between $4-5$ years experience. For good precentorship nurse preceptors should have at least

\section{Figure 1: Experience of nurse preceptors in years}

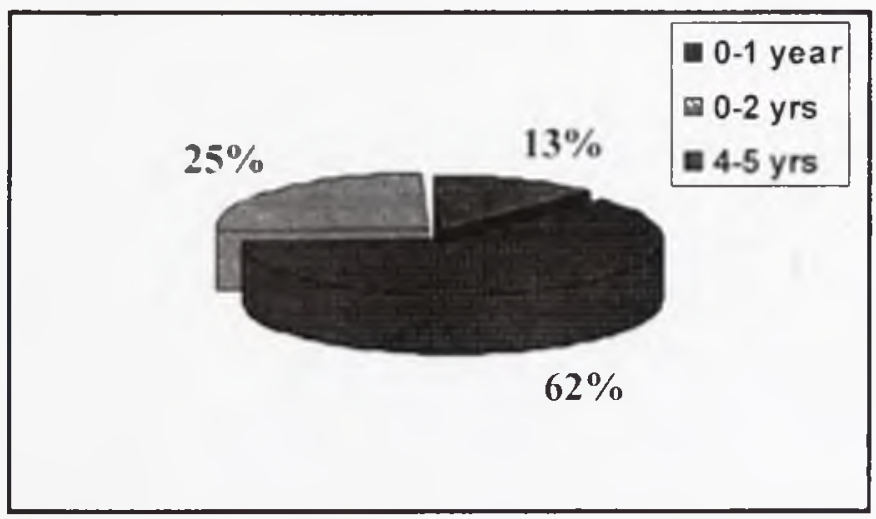

five (5) years or more experience for effectiveness (see figure 1). Burke (1994) cited in Quinn (1997:188) sees a nurse preceptor as an experienced nurse who is attached to students for a specified time-span or experience.

\section{Experience of professional nurses in years}

Findings revealed that $12,5 \%$ (5) professional nurses had 1 year experience, $25 \%(10)$ had $2-3$ years and $61,5 \%(25)$ had $4-5$

years experience as professional nurses. This could be a great advantage in student accompaniment because most of them were more experienced.

\section{Number of student nurses supervised by nurse preceptors and professional nurses}

Nurse preceptors were asked to mention the number of student nurses they managed to supervise per day in clinical areas.

Figure 2 revealed that $50 \%$ (8) nurse preceptors supervised 12 student nurses, $25 \%$ (4) supervised $3-4,18,5 \%$ (3) supervised 5-6 students and 6,5\% (1) supervised 7 and above student nurses. Most nurse preceptors managed to supervise only 12 student nurses per day out of 10 allocated including those doing a bridging course. This is not enough because each student nurse allocated in the Unit should be supervised daily for effectiveness. It means that not all student nurses are supervised which is a problem. Nurse preceptors indicated that they are unable to supervise more than that because of many roles that they are responsible for, besides clinical teaching like administration of the Unit and patient care. The nurse preceptors who managed to supervise 3-7 student nurses per day were forced to supervise as many students as possible because of high numbers. They found this to be very strenuous as they were also involved in management duties and patient care. Burke (1994) cited in Quinn (1995:188) suggested that each student nurse is supposed to be attached to the preceptor for relatively long periods of time, such as a day or a week.

Professional nurses working in the Units were also asked to mention the number of student nurses they supervise per day. Findings revealed that the majority $87,5 \%$ (35) were unable to supervise student nurses because of heavy workloads and the remaining $12,5 \%$ (5) indicated that they managed to supervise only 1 student nurse per day. It means that the rest of student nurses are expected to be supervised by nurse preceptors only. This is not fair because each and every registered nurse working in clinical areas has a teaching function of student nurses. They should all participate actively.

\section{Roles played by nurse preceptors and professional nurses in student accompaniment}

When the nurse preceptors were asked to identify the roles they play in student accompaniment, they mentioned the following:

Orientation of new student nurses in the Unit Demonstration of procedures

Assessment and evaluation of performances

Provision of clinical teaching as a whole like correlat ing theory to practice

Support and encouragement 
Professional nurses were also asked to identify roles they play in student accompaniment. The few professional nurses that mentioned that they are able to accompany student nurses mentioned the following roles and functions:

- Demonstration of procedures

- Support and encouragement when necessary

- $\quad$ solution of problems experienced by student nurses in the clinical areas

From the above findings it was clear that nurse preceptors are playing a larger role in student accompaniment as compared to professional nurses.

\section{Categories of professional nurse contributing most in student accompaniment}

Student nurses were asked to identify the categories of professional nurses who contributed most to their accompaniment by selecting from nurse preceptors, professional nurses work- fied by student nurses:

- Orientation to surroundings of the Unit, routine of the Unit and procedures

- $\quad$ Provision of assurance, support and encouragement

- Clinical teaching as a whole

- Demonstration of special procedures in the Unit

- allaying of fears and anxieties when allocated to the Unit for the first time

- always available to help them when the need arises

- $\quad$ acting as role models

- $\quad$ are knowledgeable and disseminate up-to-date infor mation about new advances in nursing especially in the clinical areas

- $\quad$ assessment or evaluation of their performance and writing of their reports

Professional nurses were also in agreement with student nurses

\section{Figure 2: Number of student nurses supervised by nurse preceptors per day}

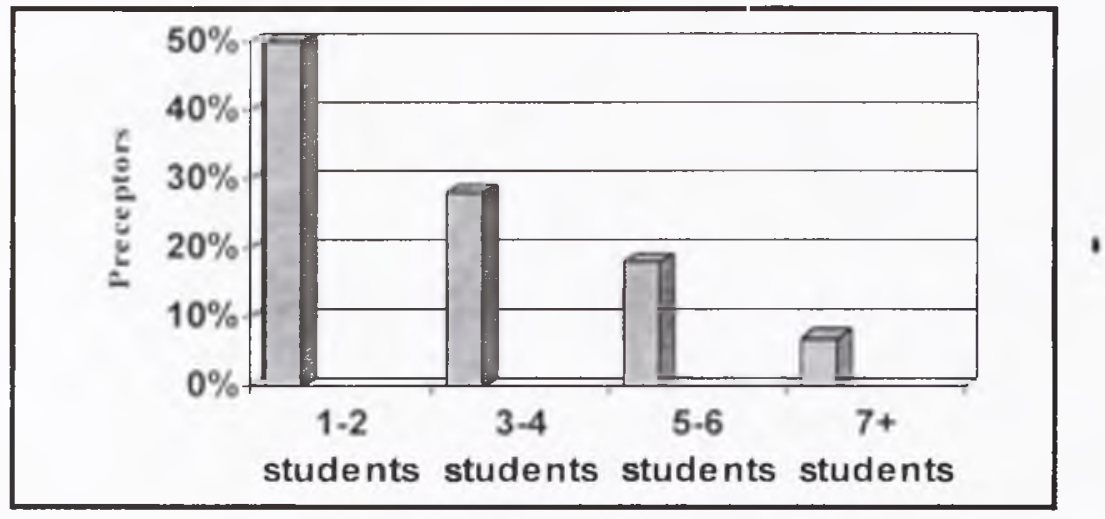

ing in the Units, clinical instructors and nurse educators. The following results were obtained:

Seventy student nurses $(87,5 \%)$ identified nurse preceptors as being the most helpful.

- $\quad \operatorname{Six}(7,5 \%)$ of student nurses identified professional nurses $4(5 \%)$ identified the clinical instructors and no student mentioned nurse educators as contributing to student accompaniment (see figure 3). It is obvious from these findings that nurse preceptors are playing a major role in student accompaniment $(87,5 \%)$ as compared to other professional nurses.

\section{Contributions of nurse preceptors in student accompaniment as perceived by student nurses}

The following contributions of nurse preceptors were identi- that nurse preceptors are of great value and that they appreciated all the help provided to student nurses by:

- $\quad$ acting as resource people for student nurses

- acting as role models for student nurses

- demonstrating all the procedures and many more contributions

In contrast French et al. (1989) in Mashaba and Brink (1994:128) stated that student nurses have reported that the most valued support in nursing practicum is that of peers with qualified practitioners a less effective option and School of Nursing staff the least effective option. This information confirms that student nurses need somebody who is always with them in clinical areas for help.

\section{Problems encountered in clinical areas}

The professional nurses, preceptors and student nurses were 
asked to mention the problems they experience in the clinical areas. The following problems were identified by each category.

\section{Problems experienced by professional nurses}

- Heavy workloads

- Shortage of staff

- $\quad$ Expected to administer the Unit, provide patient care and at the same time, to

- do clinical teaching of student nurses

\section{Problems experienced by nurse preceptors}

- Lack of resources for demonstration of procedures

- Student absenteeism interrupted continuity of clinical teaching

- $\quad$ Sometimes there is poor communication between college staff and service staff and between the nurse pre ceptors and professional nurses.

- Lack of clear job descriptions concerning their roles in student accompaniment. Booyens (1992:272) emphasised a written description of responsibilities with regard to selecting learning experiences and supervis- ing student nurses.

- $\quad$ Lack of in-service education to update their knowledge and skills. Mellish and Lock (1992:14) pointed out that nurse managers should provide in-service education to nurse preceptors for effectiveness.

- Lack of frequent meetings between college staff and service staff for discussion of problems they encounter in student accompaniment.

- Changing of shifts to do night duty which results in the neglect of teaching of student nurses.

- Nobody relieves them when they are off-duty and on leave.

- $\quad$ Expected to provide clinical teaching, management of the Unit and patient care at the same time, resulting in failure to concentrate on student accompaniment. According to Collins (1988:9) nurse preceptors need to rotate less, to become less of an all-rounder, to be come greater specialists in their Units, so that they have more pride in their Units, more confidence in their knowledge and an improved attitude towards clinical teaching.

\section{Problems experienced by student nurses in the clinical areas}

- When nurse preceptors are on leave, on night duty and off-duty nobody supervises them and no clinical teaching takes place.

\section{Figure 3: Most important category of professionals contributing most in student accompaniment}

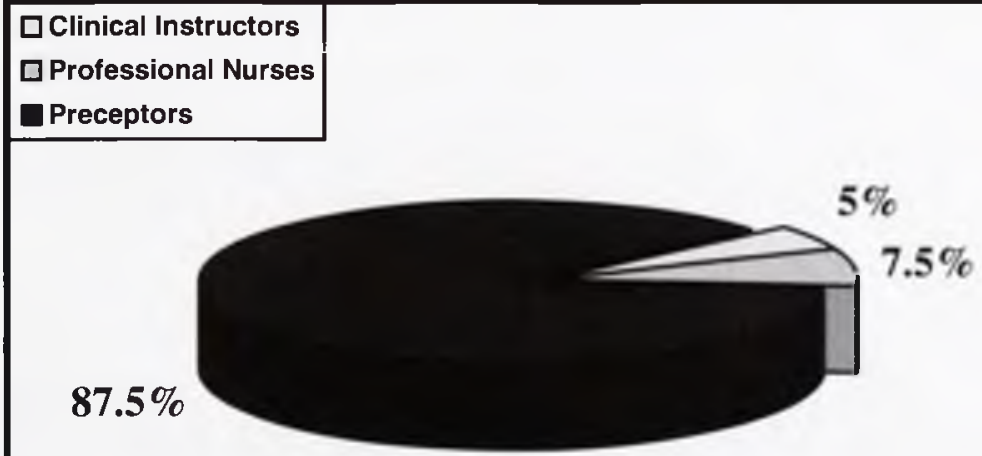




\section{Discussion}

The findings of this research revealed that clinical instruction was mostly done by nurse preceptors rather than other professional nurses, and that during their absence no active clinical teaching took place since nobody relieved them. Student nurses and professional nurses found nurse preceptors to contribute to the growth and development of student nurses. Professional nurses in the clinical areas were found not to be actively involved in clinical teaching of student nurses.

Both the professional nurses and the student nurses identified the following roles and functions of the preceptors:

- Clinical teaching of the student nurses

- $\quad$ Act as support systems to the student nurses

- $\quad$ Act as resource people because they have up-to-date knowledge on advances in nursing

- $\quad$ Orientate the student nurses when coming into the clinical areas for the first time and are always available to them

- $\quad$ Responsible for demonstration of procedure in the clinical setting

- Act as role models for the student nurses

Each and every professional nurse has teaching functions of student nurses, patients and the public at large. It is important that professional nurses working in the clinical areas, take an active part in student teaching to help the over-worked and short-staffed nurse preceptors. If this is done the present situation of lack or poor student accompaniment can improve.

Nurse preceptors identified the following problems as experienced in clinical areas about student accompaniment:

- $\quad$ Preceptors stated that they are unable to accompany many student nurses per day since there is only one preceptor per Unit, while there are about ten and more student in each Unit.

- Nurse preceptors experienced many problems in the clinical areas and there are no meetings to discuss these problems.

- Lack of resources for demonstration of procedures.

- Lack of clear job descriptions concerning their roles in student accompaniment.

- $\quad$ Nurse preceptors do night duty during which time no active student accompaniment takes place because nobody relieves them.

- Work overload and shortage of nurse preceptors.
There seems to be a general lack of in-service education programmes planned for nurse preceptors to update their knowledge and skills.

The abovementioned problems experienced by nurse preceptors in student accompaniment need to be solves promptly by senior nurse managers and senior nurse educators in order for them to perform their roles and functions effectively.

\section{Recommendations}

The results of this study allow us to come forward with several recommendations for improving the functioning of nurse preceptors.

-

Where possible, nurse preceptors should be utilized more in clinical areas instead of clinical instructors for clinical teaching since they are working closely with the student nurses for proper supervision. Clini -cal instructors are not allocated in the Units, so they are not working closely to student nurses. They only come to the Units from clinical teaching department to demonstrate procedures and other clinical teaching activities for short periods of time. Student accompa -niment can be more effective if a person doing it is available to student nurses for help whenever the need arises.

- $\quad$ Nurse preceptors should be allocated to the Units solely for clinical teaching purposes. They should under take minimal patient care and administration of the Units, not to be allocated on night duty and not to be placed in charge of the Units for continuity of student teaching and proper supervision. When on leave, should be relieved by other professional nurses.

Each Unit should have less than 10 student nurses al located because there is only one nurse preceptor allocated in each Unit for effective student accompaniment, since she will try to accompany as many of them as possible if they are less in numbers.

Professional nurses allocated in the Units, should par take actively in clinical teaching of student nurses in the absence of nurse preceptors to fill the gaps in order to improve the present lack of student accompaniment.

- If possible, regular meetings should be held by nurse managers, college staff and nurse preceptors to discuss problems experienced by nurse preceptors and improve work relationships in the workplace.

Regular in-service education programmes should be provided by nurse educators for nurse preceptors inorder to maintain effectiveness in clinical teaching. 
- Nurse preceptors should be provided with clearly defined objectives indicating the nature and extent of student learning needs in a particular Unit.

- Clear job descriptions should be provided for nurse preceptors concerning their roles and functions in stu dent accompaniment.

- $\quad$ Even those hospitals that are not using nurse precep tors for student accompaniment should consider them because of their value in student accompaniment.

\section{Conclusions}

The study revealed that nurse preceptors are playing the most important role in student accompaniment as compared to other professional nurses. Another finding is that during their absence no active clinical teaching takes place. Proper utilization of nurse preceptors can solve the present problem of poor / lack of student accompaniment in the clinical areas.

\section{References}

BOOYENS, SW 1993: Dimensions of Nursing Management. Juta: Kenwyn.

BRINK, HIL 1989: Registered nurse tutors perception of their role. Curationis. 12 (1\& 2):12-16.

BROOKES, EM \& THOMAS 1997: The perceptions and judgements of senior Baccalaureate student nurses in clinical decision-making. Advances in nursing science. March 50-69.

COLLINS, CT 1988: Article, delivered at 'The Utilization of Perceptors in Nursing Training'. (Unpublished) Grootte Schuur Hospital: Cape Town.

EWAN, C \& WHITE R 1994: Teaching nursing: a self-instructional handbook. Chapman \& Hall: London.

GOOD CHILD-BROWN, B 1986: Accompaniment of students by nurse teachers: a brief Didactic Study. Curationis, 9 (2):5-9.

MASHABA, TG \& BRINK, HIL, 1994: Nursing education: an International perspective. Juta: Cape Town.

MELLISH, JM \& WANNENBURG, L 1993: Unit teaching and Administration for Nurses $3^{\text {rd }}$ edition. Butterworth: Durban.

MELLISH, JM \& LOCK, MVLH 1992: Administration the Practice of Nursing. $2^{\text {nd }}$ edition. Butterworth: Durban.

MELLISH, JM \& BRINK, HIL 1993: Teaching the practice of Nursing. Butterworth: Durban.

QUINN, MQ 1995: The principles and practice of nurse education. $3^{\text {rd }}$ edition. Chapman \& Hall: London.
REILLY, DE \& OERMAN, MH 1992: Clinical teaching in nursing education. National League for nursing: New York.

SANC 1986: Regulations related to the approval of and the minimum requirements for the education and training of a nurse (General, Psychiatry and Community) and midwife leading to registration Regulations R425 in terms of the Nursing Act 50 of 1978 as amended.

SANC 1992: The philosophy and policy of the South African Nursing Council with regard to professional nursing education. Established under the Nursing Act 50, 1978 as amended.

TANNER, CA 1996: Evaluation of clinical competency . Journal of nursing education. 35 (2):51-53.

TROSKIE, R; GUWA, SM \& BOOYENS, SW 1998: Contribution of the Unit managers to the training of student nurses in the Cape Peninsula. Curationis. 21(4):24-28. 